BMJ

Open

Gastroenterology

\section{Haemostasis treatment using dual red imaging during endoscopic submucosal dissection: a multicentre, open-label, randomised controlled trial}

To cite: Fujimoto A, Saito Y, Abe $\mathrm{S}$, et al. Haemostasis treatment using dual red imaging during endoscopic submucosal dissection: a multicentre, open-label, randomised controlled trial. BMJ Open Gastro 2019;6:e000275. doi:10.1136/ bmjgast-2019-000275

Received 12 January 2019 Revised 19 February 2019 Accepted 2 March 2019
Check for updates

(C) Author(s) (or their employer(s)) 2019. Re-use permitted under CC BY-NC. No commercial re-use. See rights and permissions. Published by BMJ.

For numbered affiliations see end of article.

Correspondence to Dr Naohisa Yahagi; yahagi.keio@gmail.com

\begin{abstract}
Introduction Patients scheduled to undergo oesophageal, gastric and colorectal endoscopic submucosal dissection (ESD) are to be investigated to verify the efficacy of dual red imaging (DRI) for establishing haemostasis during ESD.

Methods and analysis The trial is designed as a multicentre, open-label randomised, parallel-group, controlled intervention study. Registered patients will be randomly assigned to DRI and white light imaging (WLI) groups. In the DRI group, the mucosal incision and submucosal dissection will be performed by WLI, and haemostasis will be managed by DRI when bleeding occurs. In the WLI group, the mucosal incision and submucosal dissection are to be performed by WLI and the haemostasis management is to be performed by WLI. The primary endpoint is the time from the recognition of bleeding up to the achievement of complete haemostasis (haemostasis time). The secondary endpoints are the operation time, the proportion of cases in which perforation occurs, and the psychological stress experienced by the endoscopist during haemostasis treatment.

Ethics and dissemination This trial was approved by the Keio University Review Board for Clinical Trials (5 December 2016).

Discussion This will be the first multicentre collaborative research using DRI for haemostasis treatment during ESD. When the safety and simplicity of DRI as a treatment for haemostasis during ESD can be proven, the ESD procedure can be simplified and disseminated more widely in clinical practice.

Trial registration number UMIN000025134
\end{abstract}

\section{INTRODUCTION}

Endoscopic submucosal dissection (ESD) is now widely performed in some Asian countries, as a surgical procedure for the en bloc resection of early-stage gastrointestinal cancer. So far, however, technical challenges in performing ESD have hindered the widespread adoption of the procedure in other parts of the world. ${ }^{1-3}$ Haemostasis procedure poses one of the greatest technical challenges in ESD, as the bleeding point can be difficult for the endoscopist to visualise when encountering a haemorrhage The time spent to achieve haemostasis and the poor visibility of the bleeding point during the process impose added psychological stress on the endoscopist and may also increase the risk of perforation. ${ }^{4-6}$ Recent developments and improvements in endoscopic devices and the ESD technique have shortened the operation time and improved the treatment outcomes and complication rates. ${ }^{7-9}$ Yet, few reports have offered endoscopists satisfactory methods for promptly managing bleeding events during the ESD procedure. ${ }^{10-12}$

Dual red imaging (DRI) is a novel endoscopic technology using two long-wavelength narrow-band lights (600 $\mathrm{nm}$ and $630 \mathrm{~nm})$, developed in our institute in cooperation with Olympus (Tokyo, Japan). ${ }^{13}$ Haemoglobin in blood more strongly absorbs orange light with a centre wavelength of $600 \mathrm{~nm}$ in comparison to light with a centre wavelength of 630 nm. Furthermore, light with a centre wavelength of $600 \mathrm{~nm}$ has relatively high sensitivity to changes in the density and thickness of blood in a bleeding site. When the density and thickness of the blood is different between the bleeding point and its peripheral area, it is considered that light with $600 \mathrm{~nm}$ provides more useful information regarding the differences. Therefore, DRI which uses light with $600 \mathrm{~nm}$ makes it possible to show the different between bleeding point and its peripheral area with different colours, for example, bleeding point is depicted in orange colour, the peripheral area in yellow colour (figures 1 and 2). When the endoscopist encounters an oozing haemorrhage from a vein, the colour contrast between the bleeding point and its peripheral area is dramatically enhanced by using DRI than white light imaging (WLI) as shown in 


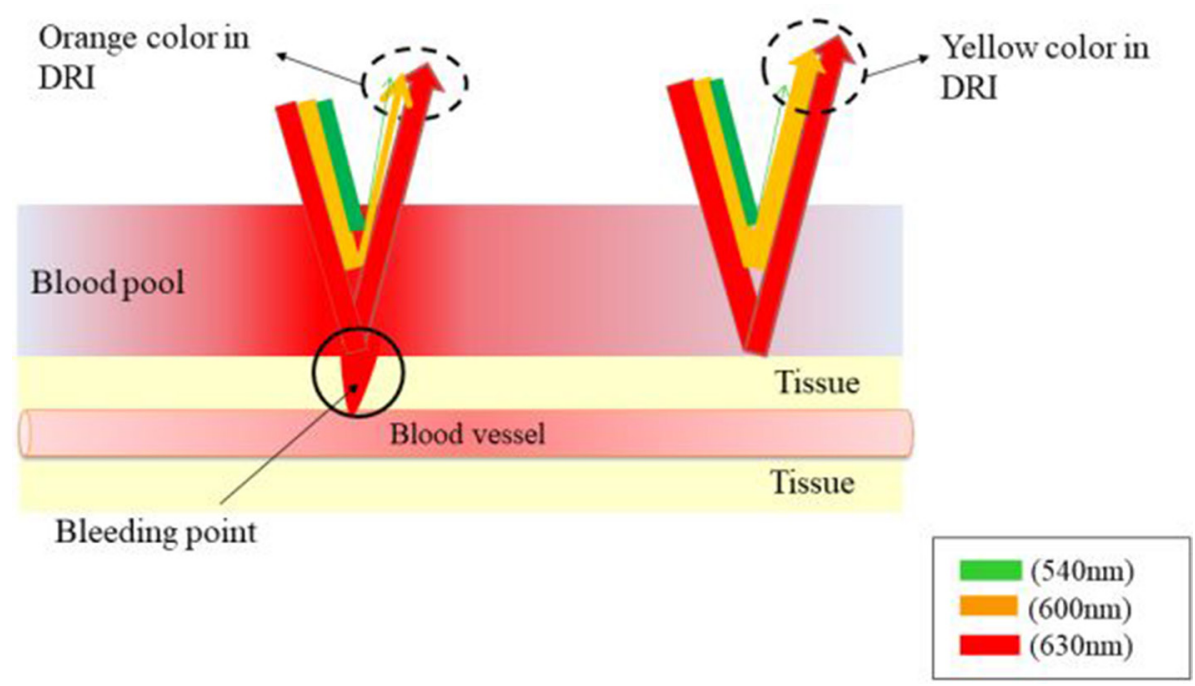

Figure 1 Mechanism for enhancing a bleeding by DRI. DRI which uses light with $600 \mathrm{~nm}$ makes it possible to express bleeding point and its peripheral area with different colours. When DRI is used, the following points are considered as the reason why the bleeding point appears clearly. (1) Haemoglobin in blood more strongly absorbs orange light with a centre wavelength of $600 \mathrm{~nm}$. (2) Light with a centre wavelength of $600 \mathrm{~nm}$ has relatively high sensitivity to changes in the density and thickness of blood in a bleeding site. When the density and thickness of the blood is different between the bleeding point and its peripheral area, it is considered that light with $600 \mathrm{~nm}$ provides more useful information regarding the differences. DRI, dual red imaging.

figure 3. We speculate that DRI could facilitate haemostasis during the ESD procedure by depicting the bleeding points in a yellow colour that can be more easily seen by the endoscopist while inducing less psychological alarm than the red colour of actual bleeding.

\section{METHODS AND ANALYSIS Study objectives}

This randomised controlled trial aims to verify the efficacy of DRI in establishing haemostasis during the ESD procedure.

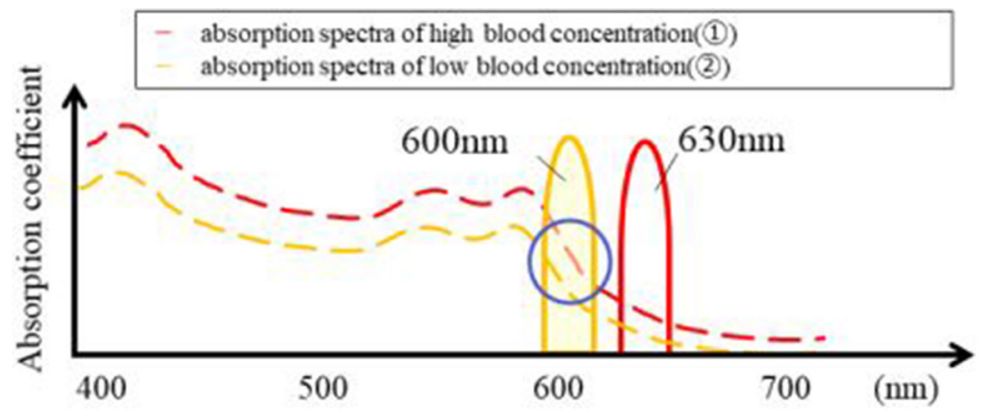

Figure 2 Mechanism for enhancing a bleeding by DRI. DRI which uses light with $600 \mathrm{~nm}$ makes it possible to express bleeding point and its peripheral area with different colours. When DRI is used, the following points are considered as the reason why the bleeding point appears clearly. (1) Haemoglobin in blood more strongly absorbs orange light with a centre wavelength of $600 \mathrm{~nm}$. (2) Light with a centre wavelength of $600 \mathrm{~nm}$ has relatively high sensitivity to changes in the density and thickness of blood in a bleeding site. When the density and thickness of the blood is different between the bleeding point and its peripheral area, it is considered that light with $600 \mathrm{~nm}$ provides more useful information regarding the differences. DRI, dual red imaging. 

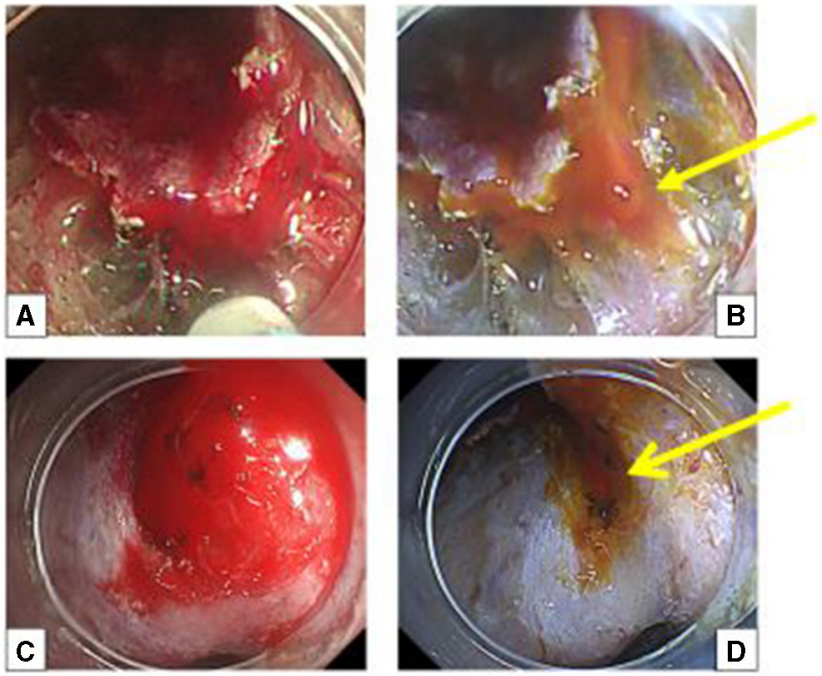

Figure 3 Difference in the visibility of the bleeding point using DRI and WLI. DRI facilitated the identification of the bleeding point due to the different rates of haemoglobin absorption in the artery and vein. $(A, C)$. WLI. (B, D) DRI. DRI, dual red imaging; WLI, white light imaging. Arrow, bleeding point.

\section{Study design}

This trial is designed as a multicentre, open-label, randomised, parallel-group, controlled intervention study.

\section{Participating centres}

- National Hospital Organization Tokyo Medical Center.

- National Cancer Center Hospital.

- Toranomon Hospital.

- St. Marianna University School of Medicine.

- Gunma University.

- The University of Tokyo.

Patients scheduled for esophagus, stomach, colon ESD

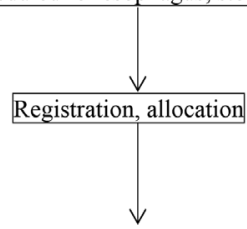

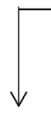

DRI group $\mathrm{n}=200$ :

WLI for mucosal incision and

Submucosal dissection. DRI for hemostasis.
WLI for mucosal incision,

submucosal dissection, and

hemostasis

Figure 4 Overall design of this study. DRI, dual red imaging; ESD, endoscopic submucosal dissection; WLI, white light imaging.

\section{Study population}

Hypotheses: Patients in the DRI group will achieve haemostasis in less time than the patients in the WLI group and endoscopists will experience less psychological stress when performing haemostasis on the DRI group than when performing haemostasis on the WLI group. The study population will consist of 400 patients evenly assigned to a standard treatment control group (WLI group, $\mathrm{n}=200$ ) and experimental treatment group (DRI group, $\mathrm{n}=200$ ) (figure 4).

The average time of one bleeding event requiring haemostasis per ESD procedure in a prior study was 50.8 $\mathrm{s}$ in a DRI group and $60.7 \mathrm{~s}$ in a WLI group. Haemostasis procedures had to be performed 1294 times in this study in order to determine the time reduction required to achieve haemostasis in the DRI group, as a result of calculation with a one-sided significance level of 0.05 and statistical power of 0.80 . On average, 3.9 haemostasis procedures were required during each ESD intervention in the prior study, so $324(1294 / 3.9)$ procedures were necessary in total. No bleeding occurred during the ESD in about $17 \%$ of the procedures in the prior study. In anticipation of drop-outs, the sample size for the current trial has been set at $n=400$ patients in total.

\section{Subjects}

Patients who used DRI for haemostasis during ESD or and patients using WLI were enrolled.

\section{Eligibility criteria}

Inclusion criteria

Patients who fulfil all of the following criteria will be included:

1. Scheduled to undergo ESD for an early-stage oesophageal, gastric or colorectal cancer (including colorectal adenoma).

2. Aged 20 years or older and 80 years or younger at the time of informed consent.

3. No pretreatment (ESD, surgery, radiation therapy, chemotherapy) has been performed in the organ to be examined.

4. Performance status of $0-1$ on the Eastern Cooperative Oncology Group standard.

5. Written consent is provided at the patient's own discretion.

6. Antithrombotic drugs are on cessation according to the guideline. ${ }^{14}$

\section{Exclusion criteria}

Patients who fulfil any of the following criteria will be excluded:

1. Haemorrhagic diathesis (platelet count $\leq 100 \times 109 / \mathrm{L}$, haemoglobin count $\leq 80 \mathrm{~g} / \mathrm{L}$ ).

2. Scheduled to undergo ESD for multiple lesions.

3. Receiving maintenance dialysis.

4. Unable to stop antiplatelet regimen at the time of informed consent. 
5. Scheduled treatment for lesions with remnant recurrence.

6. Deemed unsuitable for participation in this study by the principal investigator or other investigators.

\section{Study outline}

Treatment protocols

Patients found to have an early-stage oesophageal, gastric or colorectal cancer (including colorectal adenoma) for which ESD was indicated will be assigned to one of the two groups below. The endoscopist who carries out this study will be required to have performed more than 30 ESD procedures for each organ subject to the ESD procedure. A dual knife, hook knife and insulation-tipped diathermic (IT) knife will be used.

Standard treatment group (WLI group): After the periphery of the lesion is marked, Glyceol (10\% glyceol and $5 \%$ fructose, Chugai Pharmaceutical, Tokyo, Japan) and MucoUp (hyaluronic acid, Boston Scientific Japan, Tokyo, Japan) will be injected into the submucosal layer and a mucosal incision will be made using WLI. When bleeding is occurred during ESD, the endoscopist will establish haemostasis using WLI with haemostat or knife. Once haemostasis is established, the submucosal dissection will be continued with WLI until the lesion is resected. The definition of bleeding in this study encompasses bleeding of all types, from pulsatile bleeding to oozing. No bleeding will be assumed to occur, however, when the discharge of blood stops naturally or when only a very small amount of blood is discharged.

Experimental treatment group (DRI group): The initial marking, mucosal incision and submucosal dissection in the DRI groups will be performed by the same methods used in the WLI group. If subsequent bleeding is occurred, the endoscopist will switch to DRI immediately to confirm the bleeding point and establish haemostasis, then switch back to WLI once the haemostasis is achieved. As described above, the haemostasis treatment will be performed by switching to DRI only at times of bleeding during the procedure to fully resect the lesion.

\section{Modified treatment schedule criteria}

None specified.

\section{Concurrent and supportive therapy}

None specified.

\section{Allocation}

Patients are to be allocated to groups using an electronic data capture (EDC) system.

Method: Minimisation

Adjustment factors: Hospital, Organ.

\section{Data collection and monitoring}

\section{Data management}

An EDC system will be used to collect, monitor and manage the data from this trial. Study investigators or others designated as such will use strictly controlled personal electronic signatures (IDs and passwords) to log into the EDC system. Collected patient information will be promptly entered into the EDC and sent to a data centre. Study investigators or others designated as such will enter and correct the data, and the former will confirm the accuracy of all data input. Case report forms will be saved separately from the data to be input to EDC, scanned and imported into charts.

\section{Monitoring}

This trial will employ a centralised monitoring system based on data collected via the EDC system. The centralised monitoring of the data will be itself monitored once a month. On-site monitoring will be conducted at each facility 1 month after the start of testing.

\section{Endpoints}

\section{Primary endpoint}

The time from the recognition of bleeding up to the achievement of complete haemostasis (haemostasis time).

\section{Secondary endpoints}

1. The psychological stress experienced by the endoscopist during haemostasis treatment, as assessed on a scale of 1-5 ((1) no stress; (2) minor stress; (3) moderate stress; (4) high stress; (5) very high stress).

2. The operation time defined as the time from the start of the mucosal incision to the complete excision of the lesion.

3. Proportion of cases in which perforation occurs.

\section{Subanalysis}

1. The haemostasis time and psychological stress due to the difference in the haemostasis device used (the knife tip or haemostatic forceps (Coagrasper)).

2. The haemostasis time in ESD for each organ (oesophagus, stomach, colon, rectum).

\section{Statistical analysis}

Analysis sets

In accordance with the intention-to-treat (ITT) principle, the ITT set will consist of all cases registered and allocated to the groups in this study. The full analysis set (FAS) will be composed of all of the ITT cases except those in which treatment is cancelled for any reason after randomisation and those in which have no haemostasis treatment during ESD. Efficacy will be primarily analysed in the FAS set. The per-protocol set will be composed of all of the FAS cases except the following. With regard to the psychological stress experienced by the endoscopists during haemostasis treatment and the haemostasis time: (1) Haemostasis treatment in cases which there is an omission in the data sheet; (2) haemostasis treatment by clipping; (3) if the endoscopist is switched midway through the treatment, all haemostasis procedures after the switch; (4) treatment with haemostasis in less than $5 \mathrm{~s}$. With regard to the operation time: (1) cases in which treatment is discontinued due to adverse events, severe body movements while under procedure or poor 
circulation dynamics; (2) cases in which the endoscopist is switched during treatment; (3) cases with perforation and closure by clipping; (4) cases in which haemostasis is established not with the use of a knife or haemostat, but with clipping. The major axis of the resected specimen and the lesion site will be analysed as background data.

\section{Primary endpoint analysis}

Haemostasis time will be calculated for each group and compared between groups by the Mann-Whitney $\mathrm{U}$ test.

\section{Secondary endpoint analysis}

The operation time and psychological stress experienced by the endoscopist when working to achieve haemostasis are to be compared between the two groups by the MannWhitney $\mathrm{U}$ test. The proportion of cases in which perforation occurs will be compared between the two groups by the $\chi^{2}$ test.

\section{Subanalysis}

The haemostasis time and psychological stress experienced by the endoscopist will be calculated for each group and compared between groups by the MannWhitney U test.

\section{Interim analysis}

No interim analysis will be performed.

\section{ETHICS AND DISSEMINATION}

In order to participate in the study, the patients must provide written consent at their own free will after receiving full explanations of the study by a study investigator or research team member using an explanation-and-consent form. The explanation-and-consent form to be used meets the requirements of the Ethical Guidelines for Medical and Health Research Involving Human Subjects and has been approved for use by the Review Board for Clinical Trials.

\section{Patient safety}

Subjects will be monitored for adverse events by a study investigator or research team member. Any serious adverse event will be treated immediately and appropriately: responding team members will make efforts to ensure the subject's safety and investigate the cause of the event and will promptly report back to a study investigator by telephone or facsimile. The responses to and results of any treatment-related death will be promptly reported to the Minister of Health, Labour and Welfare if the event could not have been predicted and the researchers are unable to rule out a causal relationship between the event and this study.

\section{DISCUSSIONS}

If the results go as planned, the study will demonstrate that DRI is a novel endoscope imaging technology that effectively simplifies and facilitates the achievement of haemostasis during ESD by shortening haemostasis time and decreasing the psychological stress experienced by the endoscopist during haemostasis treatment. Naganuma et al reported that DRI was useful to assess the severity of inflammation in patients with ulcerative colitis using the deep vascular pattern. ${ }^{15}$ Ninomiya $e t$ $a l$ proposed that DRI may enhance both the safety and speed of the colorectal ESD procedure by improving the visibility of the arteries. ${ }^{16}$ Furuichi et al similarly found that DRI increased the visibility of the oesophageal varices and red colour sign. ${ }^{17}$ We also seek to verify the safety of haemostasis treatment with DRI, and the possibility of shortening the operation time by simplifying the haemostasis procedure.

Infrared endoscopy (IRE) has been found to facilitate the clear visualisation of bleeding sites during endoscopic treatment. ${ }^{12}$ The drawback of IRE is a required injection of indocyanine green, an agent that potentially induces toxic reactions such as urticaria, nausea, tachycardia or hypotension. ${ }^{18}$ In contrast, DRI requires no injection of medication, and the endoscopist can easily switch the endoscopic image from WLI to DRI with a single press of a button on the endoscope instrumentation.

It can sometimes be difficult to identify the bleeding point using WLI, because bleeding point and surrounding area are depicted in similar shades of red. Even when observing abundant bleeding with DRI, the dark yellow of the bleeding point appears in clear contrast against the surrounding ivory colour. Furthermore, the colour yellow is generally thought to uplift the emotions by eliciting feelings of optimism and confidence. ${ }^{19}$ In contrast, the red colour of the bleeding imposes added psychological stress on the endoscopist, as it puts the endoscopist on alert much like the red signal of a traffic light. We speculate, therefore, that the endoscopist can manage haemostasis with less psychological stress using DRI. For the reasons above, we presume that DRI will shorten the haemostasis time in bleeding management during ESD.

One limitation of this study should be mentioned: the psychological stress is to be evaluated subjectively based on a scale the doctors declare themselves.

\section{Author affiliations}

${ }^{1}$ Division of Research and Development for Minimally Invasive Treatment, Cancer Center, Keio University School of Medicine, Tokyo, Japan

${ }^{2}$ Department of Gastroenterology and Hepatology, National Hospital Organization Tokyo Medical Center, Tokyo, Japan

${ }^{3}$ Endoscopy Division, National Cancer Center Hospital, Tokyo, Japan

${ }^{4}$ Department of Gastroenterology, Toranomon Hospital, Tokyo, Japan

${ }^{5}$ Division of Gastroenterology and Hepatology, St Marianna University School of Medicine, Kawasaki, Japan

${ }^{6}$ Department of Gastroenterology and Hepatology, Gunma University, Maebashi, Japan

${ }^{7}$ Department of Endoscopy and Endoscopic Surgery, The University of Tokyo, Tokyo, Japan

Acknowledgements We appreciated support of Mitsuhiro Fujishiro, Masayoshi Ono, Osamu Goto, Motohiko Kato, Teppei Akimoto, Atsushi Nakayama, Yoshiyuki Kiguchi and Motoki Sasaki for this study.

Contributors AF participated in the design and statistical analysis plan of the study, and is responsible for managing data, handling monitoring. YS, SA, SH, HY, YM, TU and IS conceived of this study and participated in meetings to design the 
study and coordinate details. SA, KN, YM, SK, IS and YT submitted the design to an ethics committee at each participating institution. NY oversaw the study as chief and provided personal research funding. AF, SA, KN, YM, SK, IS, YT, TN, TM and YO were responsible for registering the cases. All of the authors read and approved this manuscript.

Funding The authors have not declared a specific grant for this research from any funding agency in the public, commercial or not-for-profit sectors.

Competing interests None declared.

Patient consent for publication Not required.

Ethics approval This study complies with the World Medical Association's Declaration of Helsinki, Ethical Guidelines for Medical and Health Research Involving Human Subjects, and Act on the Protection of Personal Information. It was approved by the Keio University Review Board for Clinical Trials (5 December 2016).

Provenance and peer review Not commissioned; externally peer reviewed.

Open access This is an open access article distributed in accordance with the Creative Commons Attribution Non Commercial (CC BY-NC 4.0) license, which permits others to distribute, remix, adapt, build upon this work non-commercially, and license their derivative works on different terms, provided the original work is properly cited, appropriate credit is given, any changes made indicated, and the use is non-commercial. See: http://creativecommons.org/licenses/by-nc/4.0/.

\section{REFERENCES}

1. Pimentel-Nunes P, Dinis-Ribeiro M, Ponchon T, et al. Endoscopic submucosal dissection: European Society of gastrointestina endoscopy (ESGE) guideline. Endoscopy 2015;47:829-54.

2. Schlachterman A, Yang D, Goddard A, et al. Perspectives on endoscopic submucosal dissection training in the United States: a survey analysis. Endosc Int Open 2018;6:E399-409.

3. Cao Y, Liao C, Tan A, et al. Meta-analysis of endoscopic submucosal dissection versus endoscopic mucosal resection for tumors of the gastrointestinal tract. Endoscopy 2009;41:751-7.

4. Tanaka S, Toyonaga T, Morita Y, et al. Efficacy of a new hemostatic forceps during gastric endoscopic submucosal dissection: a prospective randomized controlled trial. J Gastroenterol Hepatol 2017;32:846-51.

5. Toyonaga T, Nishino E, Man-I M, et al. Principles of quality controlled endoscopic submucosal dissection with appropriate dissection level and high quality resected specimen. Clin Endosc 2012;45:362-74.
6. Lee DW, Jeon SW. Management of complications during gastric endoscopic submucosal dissection. Diagn Ther Endosc 2012;2012:1-5.

7. Kikuchi D, lizuka T, Yamada A, et al. Feasibility of a newly developed thumb control device for simultaneous manipulation of the endoscope and treatment devices in endoscopic submucosal dissection: a clinical feasibility study. Digestion 2016;94:123-8.

8. Huang R, Yan H, Ren G, et al. Comparison of o-type HybridKnife to conventional knife in endoscopic submucosal dissection for gastric mucosal lesions. Medicine 2016;95:e3148.

9. Suzuki S, Gotoda T, Kobayashi Y, et al. Usefulness of a traction method using dental floss and a hemoclip for gastric endoscopic submucosal dissection: a propensity score matching analysis (with videos). Gastrointest Endosc 2016;83:337-46.

10. Libânio D, Pimentel-Nunes P, Dinis-Ribeiro M. Complications of endoscopic resection techniques for upper Gl tract lesions. Best Pract Res Clin Gastroenterol 2016;30:735-48.

11. Fujishiro M, Yoshida S, Matsuda R, et al. Updated evidence on endoscopic resection of early gastric cancer from Japan. Gastric Cancer 2017;20:39-44.

12. Ishihara R. Infrared endoscopy in the diagnosis and treatment of early gastric cancer. Endoscopy 2010;42:672-6.

13. Yahagi N, Fujimoto A, Horii J, et al. Dual read imaging: a novel endoscopic imaging technology visualizing thick blood vessels of the gastrointestinal wall. Endosc Int Open, 2018.

14. Kato M, Uedo N, Hokimoto $\mathrm{S}$, et al. Guidelines for gastroenterological endoscopy in patients undergoing antithrombotic treatment: 2017 appendix on anticoagulants including direct oral anticoagulants. Dig Endosc 2018;30:433-40.

15. Naganuma M, Yahagi N, Bessho R, et al. Evaluation of the severity of ulcerative colitis using endoscopic dual red imaging targeting deep vessels. Endosc Int Open 2017;5:E76-E82.

16. Ninomiya $Y$, Oka S, Tanaka S, et al. Clinical impact of dual red imaging in colorectal endoscopic submucosal dissection: a pilot study. Therap Adv Gastroenterol 2016;9:679-83.

17. Furuichi Y, Gotoda T, Moriyasu F, et al. Dual red imaging (novel advanced endoscopy) can increase visibility and can predict the depth in diagnosing esophageal varices. J Gastroenterol 2017;52:568-76.

18. Benya R, Quintana J, Brundage B. Adverse reactions to indocyanine green: a case report and a review of the literature. Cathet Cardiovasc Diagn 1989;17:231-3.

19. Okudaira Y, Sugiura T, Nakamura T, et al. "Physiological responses on color stimulation of video images", SCIS \& ISIS 2008:1608-12. 


\section{Correction: Haemostasis treatment using dual red imaging during endoscopic submucosal dissection: a multicentre, open-label, randomised controlled trial}

Fujimoto A, Saito Y, Abe S, et al. Haemostasis treatment using dual red imaging during endoscopic submucosal dissection: a multicentre, open-label, randomised controlled trial. BMJ Open Gastroenterology 2019;6:e000275. doi: 10.1136/ bmjgast-2019-000275

The third author's name is misspelt. The correct spelling is 'Seiichiro Abe'.

Open access This is an open access article distributed in accordance with the Creative Commons Attribution Non Commercial (CC BY-NC 4.0) license, which permits others to distribute, remix, adapt, build upon this work non-commercially, and license their derivative works on different terms, provided the original work is properly cited, appropriate credit is given, any changes made indicated, and the use is non-commercial. See:http://creativecommons. org/licenses/by-nc/4.0/.

(C) Author(s) (or their employer(s)) 2019. Re-use permitted under CC BY-NC. No commercial re-use. See rights and permissions. Published by BMJ.

BMJ Open Gastro 2019;6:e000275corr1. doi:10.1136/bmjgast-2019-000275corr1

A) Check for updates 